\title{
Natural Size Development of Myomata - Ultrasound Observational Study of 55 Premenopausal Patients
}

\author{
Natürliche Größenentwicklung von Myomen - \\ sonografische Verlaufsbeobachtung bei 55 prämenopausalen Patientinnen
}

Authors

Affiliations
M. David ${ }^{1}$, L. Adams ${ }^{1}$, J. H. Stupin ${ }^{2}$

${ }^{1}$ Clinic of Gynaecology, Charité-University Medicine Berlin, Berlin

${ }^{2}$ Clinic of Obstetrics, Charité-University Medicine Berlin, Berlin
Key words

- benign uterine tumours

- uterus

- ultrasound

Schlüsselwörter

- benigne Uterustumoren

- Uterus

- Ultraschall

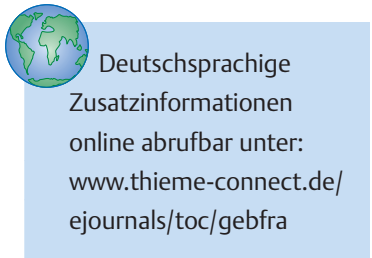

$\begin{array}{ll}\text { received } & 21.4 .2013 \\ \text { revised } & 11.10 .2013 \\ \text { accepted } & 13.10 .2013\end{array}$

Bibliography

Dol http://dx.doi.org/

10.1055/s-0033-1351072

Published online 21.1.2014

Geburtsh Frauenheilk 2014; 74:

75-80 (c) Georg Thieme

Verlag KG Stuttgart · New York

ISSN 0016-5751

\author{
Correspondence \\ Dr. Jens H. Stupin \\ Charité-University Medicine \\ Berlin \\ Clinic of Obstetrics \\ Campus Virchow Hospital \\ Augustenburger Platz 1 \\ 13353 Berlin \\ jens.stupin@charite.de
}

\section{Abstract \\ $\nabla$}

Objective: The natural growth progression of uterine leiomyomata will be studied and used to identify potential predictive criteria of myoma size development. This should answer the question of whether myoma growth is dependent on patient age, or on the localisation or original size of the myoma, as well as how much of a size increase can be expected per unit of time, and the proportion of myomata which shrink.

Patients and Methods: Patient files of a myoma surgery from 2010 to 2012 were retrospectively evaluated. The following inclusion criteria applied: diagnosis of at least one, but not more than three myomata, a minimum of two consultations within three years, the performance of a transvaginal ultrasound to determine size, no pregnancy, and no medical or surgical myoma reduction measures. Only premenopausal patients were included in the analysis. Myoma volume was approximated using a formula similar to that used to calculate the volume of an ellipsoid.

Results: 55 out of 102 patients (median age: 38 years), in which a total of 72 myomata were diagnosed, could be included in the evaluation. The median diameter of the myomata at the start of the study was $3.8 \mathrm{~cm}$, with an average growth rate of $30 \%$ over 6 months (range: -46 to $+459 \%$ ). $15 \%$ of the myomata regressed. The linear regression analysis showed a correlation between myoma growth over 6 months, the original size of the myoma $(p=0.023)$ and patient age $(p=0.038)$, but no connection was found to the localisation of the myoma. Smaller myomata decreased significantly more in size than larger myomata $(p=0.011)$. Older patients presented with larger myomata. Conclusions: Myomata demonstrate a strikingly large variation in size development. Their growth is highly individual and not ultimately predictable. Patients should be advised of the possibility of spontaneous myoma regression.

\section{Zusammenfassung \\ $\nabla$}

Ziel: Aus der Untersuchung des natürlichen Wachstumsverlaufs von uterinen Leiomyomen sollen mögliche Vorhersagekriterien der Myomgrößenentwicklung abgeleitet werden. Es soll die Frage beantwortet werden, ob das Myomwachstum abhängig vom Alter der Patientinnen, der Myomlokalisation oder -ausgangsgröße ist, sowie mit welcher Größenzunahme pro Zeiteinheit zu rechnen und wie groß der Anteil von Myomen ist, die schrumpfen.

Patientinnen und Methoden: Patientinnenakten einer Myomsprechstunde aus den Jahren 2010 bis 2012 wurden retrospektiv ausgewertet. Es galten folgende Einschlusskriterien: Diagnose von mindestens einem, aber höchstens 3 Myomen, mindestens 2 Vorstellungstermine innerhalb von 3 Jahren, Durchführung einer Vaginalsonografie zur Größenbestimmung, keine Schwangerschaft sowie keine operativen oder medikamentösen Maßnahmen zur Myomverkleinerung. Es wurden nur prämenopausale Patientinnen in die Auswertung einbezogen. Das Myomvolumen wurde durch Anwendung einer der Berechnung eines Ellipsoids ähnlichen Formel angenähert.

Ergebnisse: 55 von 102 Patientinnen (medianes Alter: 38 Jahre), bei denen insgesamt 72 Myome diagnostiziert wurden, konnten in die Auswertung eingeschlossen werden. Der Durchmesser der Myome betrug 3,8 cm (Median) zu Vorstellungsbeginn, die Wachstumsrate über 6 Monate $30 \%$ (Median, Spannweite: -46 bis $+459 \%$ ). 15\% der Myome bildeten sich zurück. In der linearen Regressionsanalyse zeigte sich eine Korrelation des Myomwachstums über 6 Monate mit der Myomausgangsgröße $(p=0,023)$ und dem Alter $(\mathrm{p}=0,038)$, jedoch kein Zusammenhang mit der Myomlokalisation. Kleinere Myome nahmen signifikant mehr an Größe zu als größere Myome $(p=0,011)$. Bei älteren Patientinnen zeigten sich größere Myome. 
Schlussfolgerungen: Myome zeigen in ihrer Größenentwicklung eine auffällig große Varianz. Das Wachstum erfolgt individuell sehr unterschiedlich und ist letztendlich nicht vorhersagbar. Patientinnen sollten auf die Möglichkeit einer spontanen Myomschrumpfung hingewiesen werden.

\section{Introduction}

$\nabla$

Myomata are the most common form of benign tumour of the female genitaltract, with an incidence of approximately 33 in every 100 women between the ages of 40 and 60 [1]. A wait-and-see approach is almost always possible in the absence of symptoms. The main reasons for treatment are symptoms associated with myomata, such as bleeding disorders, dysmenorrhoea, pressure discomfort in the lesser pelvis and fertility problems[2,3]. In accordance with current ACOG recommendations, the clinical diagnosis of "rapidly growing leiomyoma" should no longer be used as an indication for myoma enucleation or a hysterectomy $[4,5]$. When it comes to many (uninformed) patients, however, there is definitely a fear of the malignant degeneration of a myoma, while there is a fear on the medical side of overlooking a uterine sarcoma [6]. The "rapid growth" of the uterus or alleged myoma was previously regarded as a key clinical sign of a sarcoma [7].

Myomata evidently grow over a woman's entire reproductive life phase. There are however no long-term studies on myoma growth or "standard curves" for size development. In the literature, there are only 7 studies which have addressed the natural growth pattern of leiomyomata in the broader or narrower sense; 4 working groups used MRI scans to monitor the progress [8-11], while only 3 used transvaginal ultrasound, which is less expensive and more common in clinical gynaecological practice [12-14].

The aim of this clinical observation study was to record the natural growth progression of myomata in untreated, premenopausal women by means of (gynaecological) transvaginal ultrasound and to correlate this with factors such as patient age, myoma localisation and myoma size.

\section{Materials and Methods}

$\nabla$

\section{Inclusion/exclusion criteria}

As part of the study, patient records from myoma surgery at the Department of Gynaecology of a university hospital between 2010-2012 were analysed. Inclusion criteria for the selection of patients were, that

1. at least one, but not more than three myomata were diagnosed,

2. exclusively transvaginal ultrasound was used to diagnose the myoma,

3. no medical or surgical measures for myoma treatment were carried out during the study period,

4. there were a total of at least two examination appointments with the patient, which were no more than three years apart,

5. the patient was not postmenopausal,

6. the last consultation date was no farther back than 2010, and

7. the patient was not pregnant at any point during the duration of the study.

The study duration was limited to 3 years in order to ensure the comparability of the growth pattern values. The allocation "postmenopausal" was made because of the standard medical history of the patients (at least one year without menses). Uterine myomatosis was an exclusion criterion.

\section{Data collection}

For each patient, there was a filled out medical history form, in which she had self-evaluated the symptoms caused by the myomata (intensity of bleeding, pain before/during menstruation, dyspareunia, back pain, bladder pressure/frequent urination, feeling of pressure/sensation of a foreign object in abdomen, etc.) on the basis of a visual scale from 0-10 (Likert scale) [15].

\section{Examiner and examination device}

All ultrasound examinations were carried out by the same examiner (M.D.) and using the same device (Siemens Sonoline G40, Siemens Medical Solutions, Inc., Mountain View, CA, USA).

The localisation (submucous, subserous, intramural) and size of each myoma - as determined by ultrasound - was taken from the patient files.

\section{Calculation of myoma size}

This was established using a formula similar to that used to calculate the size of ellipsoids: $1 / 6 \times \mathrm{L} 1 \times \mathrm{L} 2 \times \mathrm{L} 3 \times \pi[8]$. L1, L2 and L3 here indicate the 3 diameters of the myoma, which are at right angles to one another. In the case of myomata in which information for only 2 diameters was recorded, an average of the two existing values was taken to provide the third value. Size approximated.

For the calculation of the relative change in the myoma size over six months, which seemed reasonable for comparison with other studies [9], a virtual conversion was carried out of the growth of all myomata during that period.

\section{Statistical analysis and data evaluation}

In order to determine the influence of various factors on myoma growth, a linear regression analysis was performed. Individual correlations were tested using a bivariate correlation as per Pearson, or as per Spearman for variables that were not distributed normally and not interval-scaled. Linear and multivariate regression analyses were performed using the absolute change in size (per 6 months) and percentage growth rate (per 6 months) as dependent variables, and patient age, original myoma size and myoma type as independent variables. Simple bivariate correlations occurred between age at first consultation and original myoma size, and between the presence of symptoms (associated with myomata) and age, original myoma size, myoma growth rate and myoma localisation. Accordingly, the influences of patient age, original myoma size and myoma localisation on the growth of myomata were examined, as was whether the presence of symptoms could be associated with one of the factors.

The data evaluation was performed using the statistics programme SPSS 19.0 (SPSS Inc., Chicago, IL, USA). Frequency, mean values and medians were used to determine the data according to the programme's scale. A significant relationship between two 


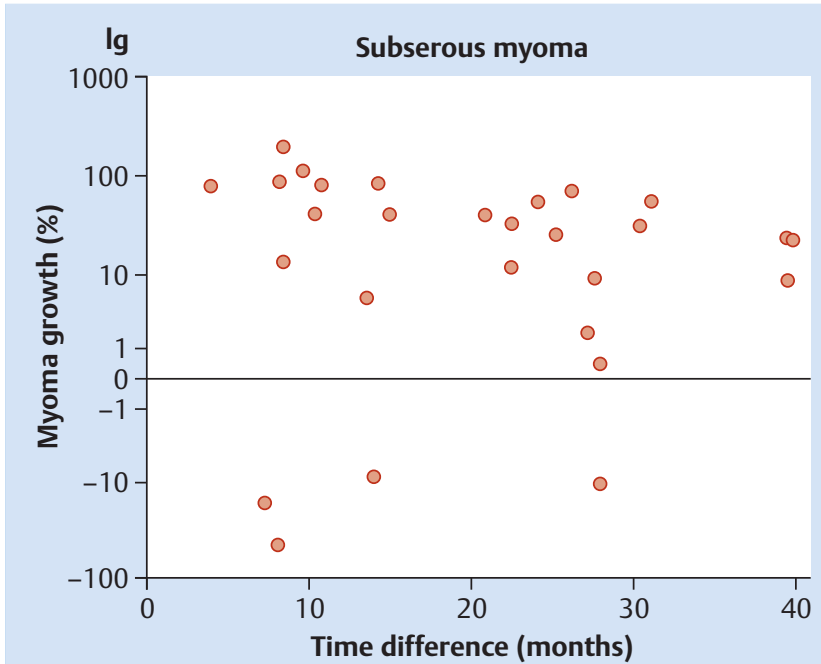

Fig. 1 Percentage myoma increase or decrease between the first and second consultation of patients in the myoma surgery in correlation with the time interval in months (subserous myoma). $\mathrm{lg}$ = logarithmic scale

characteristics was assumed when the probability of error was less than 5 per cent $(\mathrm{p}<0.05)$.

\section{Results \\ $\nabla$}

\section{Study group}

Over the course of the 3-year study period, 102 patients attended the myoma surgery at least twice. 32 women were excluded from further analysis as they had received medication and/or nonoperative myoma treatment (embolisation, focused ultrasound) in the interim. Of the 70 remaining patients, a further 9 were excluded from the study because they underwent a (uterus-preserving) surgical procedure during the observation period, a further three were postmenopausal, and a further three had received only an abdominal ultrasound due to the size of the myomata or the size of their uteri. Thus, 55 women with myomata were included in the analysis, and it was possible to track the development of a total of 72 myomata in these patients.

It is ultimately a non-randomised, yet randomly composed group.

In 16 patients, 2 or 3 myomata were present. 11 myoma patients had up to 4 examination consultations in the myoma surgery. - Table 1 shows information relating to the age (median: 38 years, range: $26-53$ years) of the women included in the analysis, their symptoms associated with myomata, the number of myomata, myomata localisation and myomata size. All patients were of Caucasian ethnicity. $58.2 \%$ of the women presented with various symptoms associated with myomata.

\section{Myoma size development}

The growth development between the first and second consultations was included in the main analysis.

The original volume of the myomata at the first consultation in the surgery ranged between 0.3 and $174.2 \mathrm{~cm}^{3}$ (median: $28.7 \mathrm{~cm}^{3}$ ). The 6 submucous myomata had a median volume of $7.7 \mathrm{~cm}^{3}$ (mean diameter: $2.45 \mathrm{~cm}$ ). Subserous and intramural myomata were similar to their original sizes. Figs. 1 and 2 show

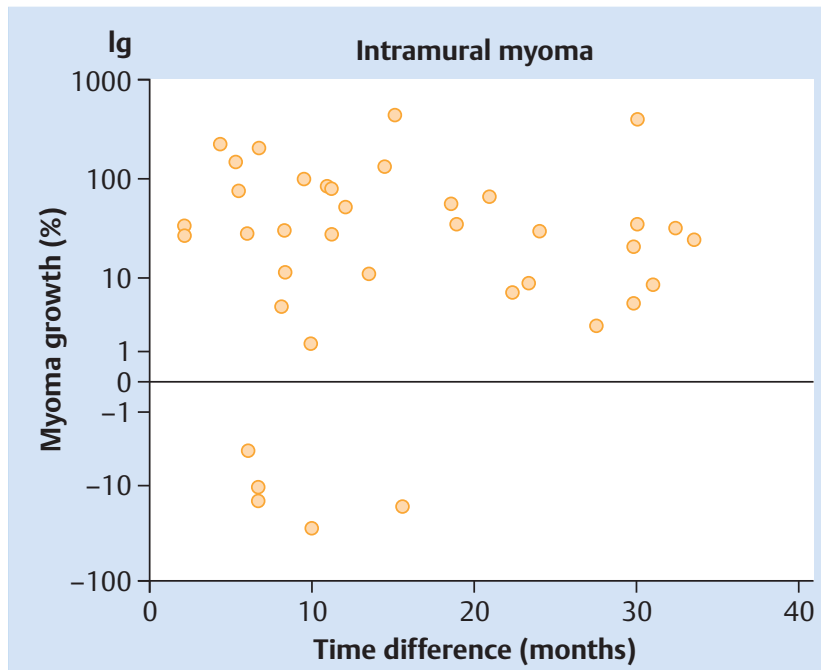

Fig. 2 Percentage myoma increase or decrease between the first and second consultation of patients in the myoma surgery in correlation with the time interval in months (intramural myoma). $\mathrm{lg}=$ logarithmic scale

the percentage myoma increase or decrease, separated by subserous and intramural localisation. There is indeed a trend here, but the comparability is limited by the fact that the patients in the surgery were not recalled according to a set follow-up interval.

The growth rates of the 72 observed myomata, which were virtually calculated over a uniform 6-month interval following the model of Peddada et al. [9], is clearer: here, the large fluctuation margin in the development of myoma volumes was shown to be between -46 and $+459 \%$ (median: $29.96 \%$ ). $50 \%$ of the myomata grew by more than $30 \%$ on average during the 6 -month interval, while $14.9 \%$ regressed ( $\bullet$ Fig. 3 ).

Influence of age, original myoma volume and original myoma localisation on the absolute and relative growth of myomata

In the case of the influence of the factors age, original myoma volume and original myoma localisation on the absolute and relative growth of myomata, a significant correlation $(p=0.006)$ was

Table 1 Patient $(n=55)$ and myoma characteristics $(n=72)$.

\begin{tabular}{|llcc|}
\hline $\begin{array}{l}\text { Patient or myoma } \\
\text { characteristic }\end{array}$ & & $\begin{array}{l}\text { Number } \\
\text { (n) }\end{array}$ & \% \\
\hline Age group & $\leq 30$ years & 7 & 12.7 \\
\hline & $31-45$ years & 42 & 76.4 \\
\hline & $>45$ years & 6 & 10.9 \\
\hline Number of myomata & one myoma & 39 & 70.9 \\
\hline & two or three myomata & 16 & 29.1 \\
\hline Symptoms associ- & present & 32 & 58.2 \\
\hline ated with myomata & & & \\
\hline & not present & 23 & 41.8 \\
\hline Myoma localisation & submucous & 6 & 8.3 \\
\hline & intramural & 38 & 52.8 \\
\hline & subserous & 28 & 38.9 \\
\hline Original myoma size & $<20$ mm & 5 & 6.9 \\
\hline & $20-50$ mm & 55 & 76.4 \\
\hline & $>50$ mm & 12 & 16.7 \\
\hline
\end{tabular}




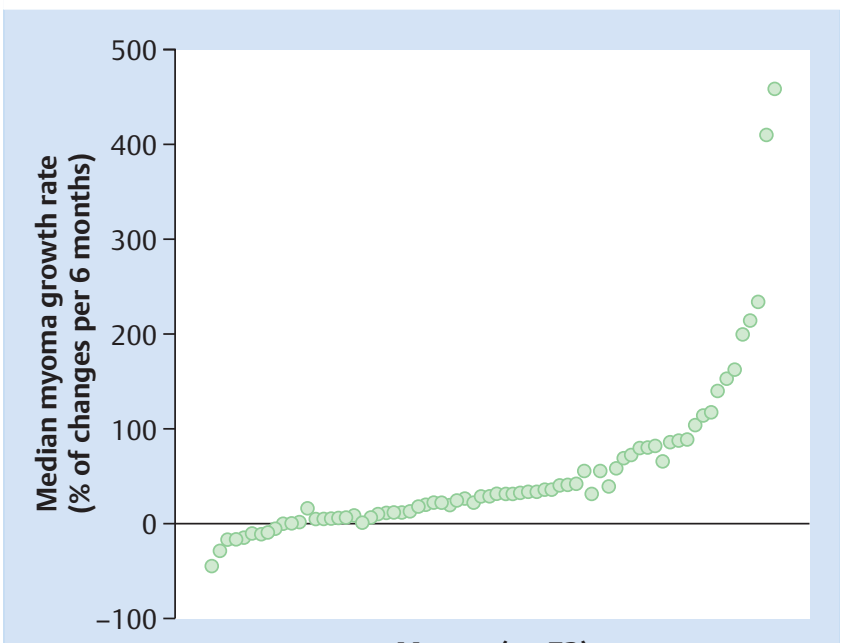

Myoma ( $\mathbf{n}=72)$

Fig. 3 Representation of the (virtually calculated) growth rates of all 72 observed myomata in a 6-month interval (modelled after [9]). Median: $29.96 \%$, fluctuation margin of myoma development: -46 to $+459 \%$.

found only for patient age; older patients were initially more likely to present with larger myomata than younger patients, but a wide margin of fluctuation was also evident here. In the case of change in myoma size between the first and second consultation in the surgery, there was a significant correlation between age and absolute growth (adjusted to a 6-month interval) $(\mathrm{p}=0.012)$.

The correlation between myoma growth and myoma localisation showed no significant difference; growth was virtually the same for intramural, subserous and submucous myomata. However, the small $(<20 \mathrm{~mm}$ diameter $)$ and average myomata $(20-$ $50 \mathrm{~mm}$ ) in the study group showed a significantly higher growth rate than the large myomata $(>50 \mathrm{~mm})(\mathrm{p}=0.011)(\odot$ Table 2$)$.

\section{Linear regression analysis}

A linear regression analysis performed using the absolute and relative change in myoma size as the dependent variable revealed a significant correlation $\left(R^{2}=0.208\right.$; ANOVA: $\left.p=0.001\right)$ between original myoma size $(p=0.023)$ and age $(p=0.038)$ for only the absolute change, i.e. the change in size in $\mathrm{cm}^{3}$ between the first and second consultations in the 6-month interval. Myoma localisation was not significantly correlated $(p=0.187)$ The correlation between symptoms associated with myomata and age, original myoma size, myoma growth rate and myoma localisation showed no significance. The multivariate analysis (0 Table $\mathbf{3}$ ) showed that the original myoma size is a significant independent predictor of myoma growth (change in size in $\mathrm{cm}^{3}$ between the first and second consultations in the 6-month interval) $\left(R^{2}=0.136, p=0.001\right)$. The addition of age into the model does not increase the significance $\left(\Delta R^{2}=0.052, p=0.001\right)$.

\section{Discussion}

$\nabla$

The aim of this study was to record the natural growth progression of myomata in untreated, premenopausal women by means of (gynaecological) transvaginal ultrasound. Surprisingly, to date there have been only a few case series and no large series of investigations. A part of the present studies on natural growth development are MRI-based $[8,10,16]$ and thus unsuitable for routine gynaecological hospital and clinical practice. Although a transvaginal ultrasound is less accurate than an MRI scan in the detection and measurement of myomata, it does represent a diagnostic method for myomata with a high degree of reproducibility, and one that can be readily integrated into any gynaecological examination [17-19].

As early as 1998, Tsuda et al. [12] had performed transvaginal and abdominal ultrasound examinations on 70 women at 3-month intervals over the course of a year (measurement of myoma volume and Doppler). They defined an essential increase in myoma volume as a change in size of at least $30 \%$, which was predominantly found in myomata in which a myoma artery could be detected (represented in 54\% of the 102 myomata studied using Doppler). Tsuda et al. [12] therefore looked at the degree of myoma blood circulation - or myoma vascularisation - as a potential predictor of myoma growth. Approximately 10 years ago, DeWaay et al. [13] published the study results of a series of studies of 64 asymptomatic women (median age: 44 years) using transvaginal ultrasound. The aim of the study was to determine the incidence and regression rates of endometrial polyps and myomata. A total of 18 myomata occurred in 11 out of 64 women (16\%). 2.5 years after the first examination, an average myoma growth of $1.2 \mathrm{~cm}(0.9$ to $6.8 \mathrm{~cm})$ was detectable. In 4 women, the myomata could no longer be seen at the second examination [13]. A third transvaginal ultrasound-based, retrospective, longitudinal study on growth progression in myomata was produced by Mavrelos et al. [14]. They were able to track 122 myoma patients between the ages of 27-45 over an 8-year period. The largest myoma in a single patient increased in volume by $35.2 \%$ per year over the study period. However, $21.3 \%$ of the myomata examined using

Table 2 Relationship between myoma localisation and size, and myoma growth ( $n=72$ ).

\begin{tabular}{|c|c|c|c|c|c|}
\hline & \multirow[t]{2}{*}{$\mathbf{n}$} & \multicolumn{2}{|c|}{ Myoma volume $\left(\mathrm{cm}^{3}\right.$, median [interquartile range]) } & \multirow{2}{*}{$\begin{array}{l}\text { Growth rate (\% per year, } \\
\text { median [interquartile range]) }\end{array}$} & \multirow[t]{2}{*}{$\mathbf{p}$} \\
\hline & & First consultation & Follow-up & & \\
\hline \multicolumn{6}{|c|}{ Myoma localisation } \\
\hline submucous & 6 & $7.7(2.7-57.9)$ & $72.4(6.5-125.1)$ & $62.0(30.0-257.0)$ & 0.456 \\
\hline intramural & 38 & $34.6(12.8-61.6)$ & $56.0(27.1-131.0)$ & $60.0(14.0-145.0)$ & \\
\hline subserous & 28 & $22.0(9.2-46.9)$ & $38.8(22.4-111.6)$ & $57.0(5.5-137.5)$ & \\
\hline \multicolumn{6}{|c|}{ Original myoma size (grouped) } \\
\hline$<20 \mathrm{~mm}$ & 5 & $1.5(0.9-3.3)$ & $8.1(1.5-21.3)$ & $234.0(77.0-612.0)$ & 0.011 \\
\hline $20-50 \mathrm{~mm}$ & 55 & $22.0(10.3-43.2)$ & $36.1(25.5-85.4)$ & $62.0(10.0-118.0)$ & \\
\hline$>50 \mathrm{~mm}$ & 12 & $106.1(91.3-125.8)$ & $151.0(128.6-196.4)$ & $35.0(22.5-153.0)$ & \\
\hline
\end{tabular}


Table 3 Results of the multivariate analysis of a prediction of myoma growth using only the original myoma size (step 1) and in combination with age (step 2).

\begin{tabular}{|llrll|}
\hline & $\boldsymbol{\beta}$ & \multicolumn{1}{c}{$\mathbf{t}$} & $\mathbf{P}$ & $\mathbf{R}^{\mathbf{2}}$ \\
\hline Step 1 & & & & \\
\hline $\begin{array}{l}\text { (Constant) } \\
\text { Original myoma size }\end{array}$ & 0.369 & -1.139 & 0.258 & 0.136 \\
\hline Step 2 & & & & \\
\hline (Constant) & & -2.319 & 0.001 & \\
\hline Original myoma size & 0.287 & 2.488 & 0.19 & 0.188 \\
\hline Age & 0.241 & 2.094 & 0.040 & \\
\hline
\end{tabular}

dependent variable: change in size in $\mathrm{cm}^{3}$ between the first and second consultations in the 6-month interval. Step 1: $R^{2}=0.136, \Delta R^{2}=0.052$ for Step $2(p=0.001)$

transvaginal ultrasound showed a significant reduction in size of at least $5 \%$ within one year, in relation to the first measurement. These values correspond in the order to the observed size increase in our study group of approximately $30 \%$ (median) and the regression rate of $15 \%$ of all myomata.

Peddada et al. [9] also reported a regression rate of $7 \%$ following a relatively short observation period of 6 months in their MRI scan study group of 72 women, which corresponded to a myoma shrinkage rate of over $20 \%$.

Mavrelos et al. [14] indicate a wide variability for myoma growth (interquartile range: 0 to $108 \%$ ), which we can confirm through our investigation.

The study results for the question of whether larger myomata or myomata with a specific localisation exhibit different growth rates are inconsistent in the literature: one (MRI-based) study showed that larger myomata show significantly less change in their short-term growth than smaller myomata [16]. Peddada et al. [9] found that myoma localisation, myoma size, BMI and parity had no influence. Mavrelos et al. [14] found a significant result from a multivariate regression analysis, which indicated that myoma size is an independent predictor of myoma growth. This is in line with the result of our investigation, which showed higher growth rates in small and medium-sized myomata.

On the whole, it therefore appears that the systematic or individual prediction of the growth behaviour of myomata for a specific patient is difficult, or virtually impossible. Obviously each myoma has a specific intrinsic growth rate, which is independent of the myoma's localisation or original size. When it comes to the size development of a myoma, it is more likely that factors at the molecular level (steroid receptors, growth factors) play a role [20], but local changes in myoma circulation may also be a factor [14]. It should be noted in the care of asymptomatic patients with myomata, as well as in treatment planning, that natural myoma regression can, in principle, occur in premenopausal women.

Limitations of the study:

1. Examiner: Ultrasound examinations can indeed be standardised, but are always dependent on the person performing the examination and its accuracy. At any rate, in the present study, the intervariability of different examiners could be excluded by restricting the study to only one examiner.

2. Design of the study: This was a retrospective analysis of routine data from a special surgery.

3. Determining myoma volumes: In the case of some myomata, for which only two diameter values were available, the third diameter was approximated by forming a mean value.
4. Examination interval: Patients were not called back in for examination after set time intervals. Therefore, for some calculations, values had to be converted to obtain a common, virtual 6-month interval.

\section{Conclusion for Clinical Practice}

$\nabla$

Overall, this clinical, transvaginal ultrasound-based study shows that the size of myoma development is rarely predictable and highly variable. Patient age and myoma size may be possible predictors of myoma growth. A natural regression rate is to be expected in myomata. The prevalence of myomata growth and regression processes and their causes should be investigated in a large prospective study in order to then be able to incorporate these findings into treatment planning or the prediction of the need for treatment.

\section{Conflict of Interest \\ $\nabla$}

None.

\section{References}

1 Lurie S, Piper I, Woliovitch I et al. Age-related prevalence of sonographically confirmed uterine myomas. J Obstet Gynaecol 2005; 25: 42-44

2 Istre 0 . Management of symptomatic fibroids: conservative surgical treatment modalities other than abdominal or laparoscopic myomectomy. Best Pract Res Clin Obstet Gynaecol 2008; 22: 735-747

3 Scheurig-Münkler C, David M, Kröncke TJ. Uterine artery embolization in patients with symptomatic fibroids: prospective long-term analysis of clinical success and changes in quality of life. Geburtsh Frauenheilk 2011; 71: 653-658

4 ACOG committee on Practice Bulletins - Gynecology. ACOG Practice Bulletin, No. 96, Aug. 2008: Alternatives to hysterectomy in the management of leiomyomas. Obstet Gynecol 2008; 112: 387-400

5 Parker WH, Fu YS, Berek JS. Uterine sarcoma in patients operated on for presumed leiomyoma and rapidly growing leiomyoma. Obstet Gynecol 1994; 83: 414-418

6 Stupin JH, Rothmann K, Kentenich $\mathrm{H}$ et al. Correlation between sonographic findings and level of knowledge/self-report of symptoms in women with uterine leiomyomata. Ultraschall in Med 2011; 32: E86E91

7 Schwartz PE, Kelly MG. Malignant transformation of myomas: myth or reality? Obstet Gynecol Clin North Am 2006; 33: 183-198

8 Ichimura T, Kawamura N, Ito F et al. Correlation between the growth of uterine leiomyomata and estrogen and progesterone receptor content in needle biopsy specimens. Fertil Steril 1998; 70: 967-971

9 Peddada SD, Laughlin SK, Miner K et al. Growth of uterine leiomyomata among premenopausal black and white women. Proc Natl Acad Sci USA 2008; 105: 19887-19892

10 Davis BJ, Haneke KE, Miner K et al. The fibroid growth study: determinants of therapeutic intervention. J Woments Health 2009; 18: 725732

11 Kasai M, Ichimura T, Kawamura $N$ et al. Prediction of the shrinking rate of uterine leiomyoma nodules using needle biopsy specimens. Fertil Steril 2012; 98: 440-443

12 Tsuda H, Kawabata M, Nakamoto O et al. Clinical predictors in the natural history of uterine leiomyoma: preliminary study. J Ultrasound Med 1998; 17: 17-20

13 DeWaay DJ, Syrop CH, Nygaard IE et al. Natural history of uterine polyps and leiomyomata. Obstet Gynecol 2002; 100: 3-7

14 Mavrelos D, Ben-Nagi J, Holland T et al. The natural history of fibroids. Ultrasound Obstet Gynecol 2010; 35: 238-242

15 Likert R. A technique for the measurement of attitudes. Arch Psych 1932; 140: 1-55

16 Baird DD, Garrett TA, Laughlin SK et al. Short-term change in growth of uterine leiomyoma: tumor growth spurts. Fertil Steril 2011; 95: 242246 
17 Malartic C, Morel O, Rivain AL et al. Evaluation of symptomatic uterine fibroids in candidates for uterine artery embolization: comparison between ultrasonographic and MR imaging findings in 68 consecutive patients. Clin Imaging 2013; 37: 83-90

18 Griffiths A, terHaar G, Rivens I et al. High-intensity focused ultrasound in obstetrics and gynecology: the birth of a new era of noninvasive surgery? Ultraschall in Med 2012; 33: E8-E15
19 David M, Kröncke T. Uterine fibroid embolisation - potential impact on fertility and pregnancy outcome. Geburtsh Frauenheilk 2013; 73: 247255

20 Ciarmela P, Islam MS, Reis FM et al. Growth factors and myometrium: biological effects in uterine fibroid and possible clinical implications. Hum Reprod Update 2011; 17: 772-790 